\title{
The effect of psychological factors on Syrian refugees' participation in lifelong education
}

\author{
Mehmet Fatih Karacabey ${ }^{1}$, Kivanc Bozkus ${ }^{2}$ \\ ${ }^{1}$ Department of Educational Sciences, Harran University, Turkey \\ ${ }^{2}$ Department of Educational Sciences, Artvin Coruh University, Turkey
}

\begin{tabular}{l} 
Article Info \\
\hline Article history: \\
Received Nov 18, 2018 \\
Revised Nov 20, 2018 \\
Accepted Jan 26, 2019 \\
\hline
\end{tabular}

\section{Keywords:}

Effect

Lifelong education

Psychological factors

Structural equation modeling

\begin{abstract}
The purpose of this research was to determine the effect of psychological factors on Syrian refugees' participation in lifelong education. The ex post facto co-relational causal design was employed in this research. A questionnaire form consisted of four scales was used to collect data from 297 refugees participated in lifelong education. The structural equation modeling analysis revealed that psychological factors affect participation in lifelong education and learning approaches played the biggest role in this effect. It was claimed that learning approach is a strong predictor of participation in lifelong education. The effect of locus of control on participation in lifelong education was medium while the effects of self-efficacy and self-worth were weak. Recommendations to education providers, decision-makers and researchers to align both formal and lifelong education curricula with the results were given.
\end{abstract}

Copyright (C) 2019 Institute of Advanced Engineering and Science. All rights reserved.

\section{Corresponding Author:}

Mehmet Fatih Karacabey, Department of Education Sciences, Harran University, Harran Üniversitesi Eğitim Fakültesi Osmanbey Yerleşkesi, 63300, Şanlıurfa, Turkey.

Email: mfkaracabey@harran.edu.tr

\section{INTRODUCTION}

Knowledge of why people participate in lifelong education is vital information for education providers and decision-makers. Because adults participate in lifelong education voluntarily, knowing what drives them to participate can help education providers and decision-makers better serve lifelong education participators. If the factors that affect participation decisions are known then the curriculum of formal education could be developed to make students have the characteristics to enable them to continue to lifelong education after graduation. Also, the curriculum of lifelong education activities could be better designed to meet the needs of those who are likely to participate.

Since lifelong education is not compulsory, the choice of participation in it largely depends on individual needs. Communication, social contact, educational preparation, professional advancement, family togetherness, social stimulation, and cognitive interest were determined as the individual needs affecting participation in lifelong education [1]. Research revealed that educational attainment to be "the most important single factor predicting participation in adult education and training" [2]. Besides these needs, psychological and social factors may influence participation [3]-[6]. The author in [7] asserts that "adults have a deep psychological need to be generally self-directing" (p. 43). Participation is related to adults' readiness to learn and individual consciousness [8].

This research tries to determine the effect of psychological factors on Syrian refugees' participation in lifelong education. Since the refugees escaped from the civil war in Syria, their psychology might be devastated. Most of them took shelter in Turkey, so there are many refugees accessible by the authors of this research. Lifelong education activities are provided to these refugees by the Turkish government. Knowing 
who participates may allow policymakers to make the activities better suitable to the needs of those who participate. Self-efficacy, self-worth, learning approach and locus of control are the selected variables for this research. These were selected because they were linked theoretically to the participation in lifelong education and their data collection tools were readily available in the Arabic language. The paper goes on defining these four variables and explaining the methodology of this research. Then the findings are presented along with their discussion. Finally, some recommendations are given to education providers, decision-makers and researchers.

\subsection{Self-efficacy}

Individuals choose tasks that they can handle. Their decisions to choose a task suitable to their abilities are based on a belief in their capacity to overcome the task. This belief in one's being efficacious in a chosen task is defined as self-efficacy by the author in [9]. It is a perception developed from gaining skills and experience gradually [10]. Thus, success increases self-efficacy while failure decreases it. This makes self-efficacy an important factor that affects human behavior and initiative. Because people behave according to their perception of self-efficacy instead of how knowledgeable and skillful they actually are [9]. If individuals anticipate failure they lose initiative and tend to avoid tasks like lifelong education [11].

\subsection{Contingencies of self-worth}

People subjectively evaluate their own worths and make judgments toward their selves expressed as beliefs like "I am worthy/worthless". These judgments are based on success and failures in domains named others' approval, physical appearance, defeating others in competition, academic competence, family love, virtue, and faith. Contingencies of self-worth influence "the situations people select for themselves, their efforts in those situations, and their reactions to successes and failures in those situations" [12]. Thus, individuals may tend to avoid situations like lifelong education if they have negative judgments of self-worth.

\subsection{Learning approach}

Adult learners are self-directed learners who are motivated either intrinsically or extrinsically. Those who learn to pass exams try to acquire only basic knowledge that may appear on exams. Their external motivation for passing exams drives them to exhibit surface learning [13]. On the other hand, those who learn to satisfy their personal growth try to grasp underlying mechanisms, causality, and principles besides acquiring only basic knowledge. Thus, they exhibit deep learning with the intrinsic motivation of selfsatisfaction [13], and these individuals may be more likely to participate in lifelong education activities for their personal growth.

\subsection{Locus of control}

Some people believe that they have control over their own life, so the outcomes of their actions are results of their abilities, behaviors, and choices. In contrast, some people believe that their life is controlled by outside forces, fate or other people, so they praise or blame these external factors for the outcomes of events in their lives. Locus means location in Latin. In the first situation, people have an internal locus of control that makes responsible their internal factors for the results of events, and in the second situation, people have an external locus of control assuming that results derive from external factors [14]. Locus of control plays a role in adult education attrition [11]. Individuals with a strong internal locus of control are likely to remain in lifelong education activities.

\section{RESEARCH METHOD}

The ex post facto co-relational causal design was employed in this research [15]. Since the research variables already exist in nature and they cannot be manipulated, experimentation is not possible, so this design is better suited to reveal the causality link among the variables [16].

The population consists of 1375 Syrian refugees sheltered in Şanllurfa province in Turkey and participating in lifelong education courses provided by the Turkish government. Using the random sampling technique 350 of the participators was selected as the sample of this research. When returning forms were processed to eliminate wrong-filled ones, 297 people constituted the sample. As seen in Table 1, 107 participants were male while 177 were female. Since the participants are vulnerable refugees, ethical precautions were made. The participation in the research was based on volunteerism. The credentials of the participants were kept as private. The participants were acknowledged of their rights. It was guaranteed that the responses would not affect the education, work, or any other aspects of life in any way. 
Table 1. Exploratory statistics of the research participants

\begin{tabular}{clcc}
\hline Variable & Groups & Frequency & Percentage (\%) \\
\hline \multirow{3}{*}{ Gender } & Male & 107 & 36 \\
& Female & 177 & 62 \\
& Not specified & 13 & 4 \\
\hline & $18-21$ & 16 & 5.4 \\
& $22-25$ & 32 & 10.8 \\
\multirow{5}{*}{ Age } & $26-29$ & 73 & 24.6 \\
& $30-33$ & 49 & 16.5 \\
& $34-37$ & 38 & 12.8 \\
& $38-70$ & 54 & 18.2 \\
& Not specified & 35 & 11.8 \\
\hline \multirow{2}{*}{ Working } & Yes & 246 & 83 \\
Status & No & 24 & 8 \\
& Not specified & 27 & 9 \\
\hline \multirow{3}{*}{ Education } & Middle School & 203 & 68 \\
Level & High School & 50 & 17 \\
& University & 26 & 9 \\
& Not specified & 18 & 6 \\
\hline
\end{tabular}

A questionnaire form consisting of four scales was used to collect data from the sample. The form included instructions on how to answer to these scales and demographic questions about gender, age, working status, and education level.

\subsection{Self-efficacy scale}

To measure the self-efficacy perceptions of the participants the General Self-Efficacy Scale developed by authors in [17] was used. It assesses the perceived self-efficacy of adults by predicting adaptation after life changes or stressful life events. It has 10 items based on a 4-point Likert scale and ranging from " $1=$ not at all true" to "4= exactly true." An example item reads like this: "It is easy for me to stick to my aims and accomplish my goals." Higher scores mean better adaptation after stressful life events. The scale is unidimensional meaning that it has no subfactors. None of the items require recoding. The reliability coefficient was calculated as $\alpha=0.82$ by using data collected in this research. To validate its unidimensional structure, a confirmatory factor analysis (CFA) based on maximum likelihood estimation was done by using data collected in this research. CFA results indicated a good fit $\left(\chi^{2} / \mathrm{df} 2.60, \mathrm{GFI}=0.94, \mathrm{CFI}=0.92, \mathrm{IFI}=0.92\right)$ according to [18].

\subsection{Self-worth scale}

The self-worth perceptions of the participants were assessed through the Contingencies of Self-Worth Scale developed by authors in [19]. It assesses how people are likely to state their self-worth according to seven domains of self-worth. It has 35 items based on a 7-point Likert scale and ranging from " $1=$ strongly disagree" to "7= strongly agree." An example item reads like this: "My self-worth is not influenced by the quality of my relationships with my family members." The scale has 7 subfactors named family support, competition, appearance, God's love, academic competence, virtue, and approval from others. Seven of the items require recoding. The reliability coefficient was calculated as $\alpha=0.74$ by using data collected in this research. CFA results indicated a good fit $(\chi 2 / \mathrm{df} 2.65, \mathrm{GFI}=0.92, \mathrm{CFI}=0.92, \mathrm{IFI}=0.91)$ according to [18].

\subsection{Learning approach scale}

Participants' approaches to learning were determined by the revised two-factor Study Process Questionnaire which was developed by authors in [20]. It assesses how deep people approach learning. It has 20 items based on a 5-point Likert scale and ranging from " $1=$ never" to "5 = always" An example item reads like this: "My aim is to pass the course while doing as little work as possible." The scale has 2 subfactors named deep learning approach and surface learning approach. No items require recoding. The reliability coefficient was calculated as $\alpha=0.79$ by using data collected in this research. CFA results indicated a good fit $(\chi 2 / \mathrm{df} 1.81, \mathrm{GFI}=0.91, \mathrm{CFI}=0.88, \mathrm{IFI}=0.88)$ according to [18].

\subsection{Locus of control scale}

Multidimensional Locus of Control Scale developed by authors in [21] was used to assess how a person perceives the primary causation of events in the life. It has 24 items based on a 5-point Likert scale and ranging from " $1=$ strongly disagree" to " $5=$ strongly agree." An example item reads like this: "To a great extent my life is controlled by accidental happenings." The scale has 3 subfactors named internal locus of control, powerful others, and chance. No items require recoding. The reliability coefficient was calculated as 
$\alpha=0.78$ by using data collected in this research. CFA results indicated a good fit $(\chi 2 / \mathrm{df} 2.01, \mathrm{GFI}=0.93$, $\mathrm{CFI}=0.90$, IFI $=0.90$ ) according to $[18]$.

The structural equation modeling (SEM) analysis technique was used in this research. It is a multivariate statistical technique ideal for the analysis of more than two variables [22]. It generally requires samples bigger than 200 people [23]. SEM allows testing of presumed relationships among multiple variables.

\section{RESULTS AND ANALYSIS}

Descriptive statistics of the research variables are presented in Table 2. The mean of self-worth $(\mathrm{X}=5.43, \mathrm{SD}=0.93)$ is at "agree" level and indicates that the participants have positive judgments of selfworth. The mean of self-efficacy $(\mathrm{X}=2.96, \mathrm{SD}=0.46)$ is at "moderately true" level, so the participants see themselves as self-efficient. The mean of learning approach $(\mathrm{X}=3.22, \mathrm{SD}=0.54)$ is at "sometimes" level. Claiming that the participants' learning approach falls under neither deep learning nor surface learning categories would be wrong. Because this variable has two competing subfactors named deep and surface learning. One-sample t-test reveals that deep learning approach $(X=3.74, S D=0.64)$ is statistically higher than surface learning approach $(\mathrm{X}=2.72, \mathrm{SD}=0.74, \mathrm{t}(296)=100.66, \mathrm{p}<0.001)$. Therefore, the participants' deep learning approach is dominant. The mean of locus of control $(X=3.27, \mathrm{SD}=0.49)$ is at "neutral" level. Onesample t-test reveals that internal locus of control subfactor $(X=3.35, \mathrm{SD}=0.64)$ is statistically higher than other subfactors $(\mathrm{t}(296)=90.69, \mathrm{p}<0.001)$ meaning that internal factors of participants have more control over their lives.

Table 2. Descriptive statistics of the research variables

\begin{tabular}{cccl}
\hline & Mean & SD & \multicolumn{1}{c}{ Level } \\
\hline Self-Worth & 5.43 & 0.93 & Agree $(6 / 7)$ \\
Self-Efficacy & 2.96 & 0.46 & Moderately True (3/4) \\
Learning Approach & 3.22 & 0.54 & Sometimes $(3 / 5)$ \\
Locus of Control & 3.27 & 0.49 & Neutral $(3 / 5)$ \\
\hline
\end{tabular}

Analysis findings indicate statistically significant correlations among self-worth, self-efficacy, learning approach and locus of control at the $\mathrm{p}<0.001$ level (Table 3 ). Correlations between self-worth and self-efficacy $(\mathrm{r}=0.18, \mathrm{p}<0.001)$, self-worth and learning approach $(\mathrm{r}=0.20, \mathrm{p}<0.001)$, self-worth and locus of control ( $\mathrm{r}=0.22, \mathrm{p}<0.001)$, self-efficacy and locus of control $(\mathrm{r}=0.23, \mathrm{p}<0.001)$ were very weak. Correlations between self-efficacy and learning approach $(\mathrm{r}=0.29, \mathrm{p}<0.001)$, the locus of control and learning approach $(\mathrm{r}=0.46, \mathrm{p}<0.001)$ were weak. The findings allow SEM analysis to assume these four variables as independent variables and participation in lifelong education as the dependent variable. Because of weak correlations indicate little or no causality among the independent variables which should affect the dependent variable.

Table 3. Correlations between the research variables

\begin{tabular}{llll}
\hline & Self-Worth & Self-Efficacy & Learning Approach \\
\hline Self-Efficacy & $0.18^{*}$ & & \\
Learning Approach & $0.20^{*}$ & $0.29^{*}$ & \\
Locus of Control & $0.22^{*}$ & $0.23^{*}$ & $0.46^{*}$ \\
*p $<0.001$ & & &
\end{tabular}

SEM analysis findings presented in Table 4 indicate a very good model fit $(\chi 2 / \mathrm{df}=1.3, \mathrm{GFI}=0.99$, $\mathrm{AGFI}=0.98, \mathrm{CFI}=0.99, \mathrm{IFI}=0.99, \mathrm{RMSEA}=0.03, \mathrm{RMR}=0.01)$ according to $[18]$. The standardized regression weight for the effect of learning approach on participation in lifelong education was at $\beta=0.71$ level $(\mathrm{p}<0.001)$. This is a strong effect indicating that when learning approach goes up by one standard deviation, participation in lifelong education goes up by 0.71 standard deviations. It can be claimed that learning approach is a strong predictor of participation in lifelong education. Locus of control affects participation in lifelong education at $\beta=0.64$ level $(p<0.001)$. It can be considered a medium effect. The effects of selfefficacy $(\beta=0.40, p<0.001)$ and self-worth $(\beta=0.32, p<0.001)$ on participation in lifelong education were weak. 
Table 4. Standardized regression coefficients

\begin{tabular}{rc}
\hline & Participation in Lifelong Education \\
\hline Learning Approach & $0.71^{*}$ \\
Locus of Control & $0.64^{*}$ \\
Self-Efficacy & $0.40^{*}$ \\
Self-Worth & $0.32^{*}$ \\
\hline $\mathrm{p}<0.001$ &
\end{tabular}

The findings of this research imply that psychological factors affect participation in lifelong education. This is consistent with previous research [3], [4], [6]. Therefore, psychological guidance should be given importance in formal education. The effect of other variables should be investigated through quantitative research methods. Knowing what variables affect participation in lifelong education and how much they affect it may guide educators to focus on the most effective psychological factors when providing psychological guidance.

It can be argued that those who have positive approaches to learning like deep learning are more willing to participate in lifelong education because the learning approaches have the biggest effect on participation in lifelong learning. This is consistent with previous research, for lifelong learning was found to be positively related to the deep learning approach and negatively to the surface learning approach [24]. The desire for learning is crucial for the continuation of lifelong education [25], [26]. The learning approaches affect the learning success [27], [28], so the importance of that individual having positive learning approaches is once more evident. Since lifelong education has become a necessity, it can be said that individuals must have positive learning approaches so that they can continue lifelong education after graduating from formal education. Steps should be taken to have students in formal education get positive learning approaches. Deep learning approach should be favored over surface learning approach. Students should be encouraged to understand why they learn what they learn. They should avoid bare memorization to pass the exams. Teachers should use evaluation methods that are able to facilitate deep learning [29].

Locus of control has the second biggest effect on participation in lifelong education. Participants of this research have an internal locus of control. So, they believe that the outcomes of their actions like participation in lifelong education are results of their abilities, behaviors, and choices instead of external factors like powerful others and chance. For example, internal locus of control may lead to learning achievement [30], [31]. Also, the locus of control plays a role in learner persistence in lifelong education [32], [33], [11]. It can be claimed that individuals with a strong internal locus of control are likely to participate in lifelong education activities. Therefore, some precautions should be adopted to make students in formal education believe that their learning success is the result of their own efforts.

The effect of self-efficacy on participation in lifelong education was weak. A similar result has been achieved in previous research. The relation between self-efficacy and lifelong learning tendency was found as significant, but weak $(\mathrm{r}=0.244, \mathrm{p}<0.05)$ by authors in [34]. However, having good self-efficacy and attending to lifelong education were found to be the determinants of good quality of life in older adults aged 60 and over [35]. Also, self-worth affects participation in lifelong education weakly. The author in [36] claims that self-worth should be an outcome of lifelong education by stating that: "the social purpose of lifelong education ought to be about developing self-worth and identity amongst individuals and communities" (p. 816).

This research has some limitations that may limit the interpretation of the findings. Since the sample was comprised of refugees in Turkey, the generalization of findings may not apply to other groups of lifelong education participants. Second, the ex post facto design employed in this research may not reveal the whole link of causality between independent and dependent variables. Future research should employ experimental designs to reveal a stronger link of causality. Third, this research used cross-sectional data that may result in unidirectional inferences among variables. To achieve an understanding of multiple relationships among the variables, future research should use longitudinal data. Fourth, the self-reported nature of data collected in this research may be subject to participant subjectivity. Alternative data collection techniques should be adopted to overcome this issue. Lastly, this research included four variables that affect participation in lifelong education. There could be other variables that may play a role in this effect.

\section{CONCLUSION}

It is concluded that psychological factors affect participation in lifelong education and learning approaches play the biggest role in this effect. Both formal and lifelong education curricula should aim to make students develop a deep approach to learning. The curriculum of lifelong education should be aligned with deep learning needs of the participants. The curricula should focus on employing analysis, synthesis, 
and evaluation in learning and thinking rather than summarization and memorization. The essence of learning should be emphasized while learning to pass exams should be discouraged. Students should have an internal locus of control. To achieve this, student success should derive from the efforts of students. Teacher favoritism and a chance of measurement errors should be diminished. Teachers should make students feel self-efficient by enabling them to achieve success. Student tasks should be appropriate to class level, so students can finish tasks without too much hassle. Similarly, teachers should avoid situations that make students feel worthless. Judging them in front of the class, harsh punishments to trivial errors and humiliation may damage self-worth perceptions of students.

\section{ACKNOWLEDGMENT}

This paper is an extended version of an oral presentation communicated at the 12th International Congress of Educational Administration, Ankara, Turkey, 2017.

\section{REFERENCES}

[1] Boshier R., "Psychometric properties of the alternative form of the education participation scale," Adult Education Quarterly, vol. 41(3), pp. 150-167, 1991.

[2] Boudard. E., \& Rubenson. K., "Revisiting major determinants of participation in adult education with a direct measure of literacy skills," International Journal of Educational Research, vol. 39(3), pp. 265-281. 2003.

[3] Boeren. E., "Lifelong learning participation in a changing policy context," Palgrave Macmillan, Hampshire, 2016.

[4] Feldman. D. C., \& Ng. T. W. H., "Participation in Continuing Education Programs: Antecedents, Consequences, and Implications," In Manuel London (Ed) The Oxford handbook of lifelong learning (ss. 180-194). New York: Oxford University Press. 2011.

[5] Günüç. S., Odabaş1. H. F., \& Kuzu. A., "Yaşam boyu öğrenmeyi etkileyen faktörler," Gaziantep Üniversitesi Sosyal Bilimler Dergisi, vol. 11(2), pp. 309-325, 2012.

[6] Merriam. S. B., Caffarella. R. S., \& Baumgartner. L. M., "Learning in adulthood: A comprehensive guide (3. ed)," John Wiley \& Sons, San Francisco, 2007.

[7] Knowles. M. S.," Bandura. A., "Social foundations of thought and action: a social cognitive theory," NJ: PrenticeHall, Englewood Cliffs 1986.

[8] The modern practice of adult education: From pedagogy to andragogy (2nd ed.)," Cambridge Books, New York, 1980.

[9] Rubenson. K., "Adults' Readiness to Learn: Questioning Lifelong Learning for All," Adult Education Research Conference, [Online]. Available : http://newprairiepress.org/aerc/1998/papers/45, 1998.

[10] Bandura, A. "Self-efficacy: the exercise of control," NY: W. H. Freeman and Company, New York 1997.

[11] Tyler-Smith. K., "Early attrition among first time eLearners: A review of factors that contribute to drop-out, withdrawal and non-completion rates of adult learners undertaking eLearning programmes," Journal of Online learning and Teaching, vol2(2), pp. 73-85, 2006.

[12] Crocker. J., "Contingencies of self-worth: Implications for self-regulation and psychological vulnerability," Self and Identity, vol. 1(2), pp. 143-149. 2002.

[13] Gibbs. G., "Improving the quality of student learning," Technical and Educational Services, Bristol, 1992.

[14] Rotter. J. B., "Generalized expectancies for internal versus external control of reinforcement," Psychological Monographs: General \& Applied, vol. 80(1), pp. 1-28, 1966.

[15] Cohen. L., Manion. L., \& Morrison. K., "Research methods in education (6. ed.)," Routledge, New York, 2007.

[16] Fraenkel. J. R., Wallen. N. E., \& Hyun. H. H., "How to design and evaluate research in education (8. ed.)," McGraw-Hill, New York, 2012.

[17] Schwarzer. R., \& Jerusalem. M., "Generalized self-efficacy scale," In J. Weinman, S. Wright, \& M. Johnston, Measures in health psychology: A user's portfolio. Causal and control beliefs (ss. 35-37), NFER-NELSON, Windsor, UK, 1995.

[18] Hu. L. T., \& Bentler. P. M., "Cutoff criteria for fit indexes in covariance structure analysis: Conventional criteria versus new alternatives," Structural equation modeling: a multidisciplinary journal, vol. 6(1), pp. 1-55, 1999.

[19] Crocker. J., Luhtanen. R., Cooper. M. L., \& Bouvrette. S. A., "Contingencies of self-worth in college students: Measurement and theory," Journal of Personality and Social Psychology, vol. 85, pp. 894-908. 2003.

[20] Biggs. J., Kember. D., \& Leung. D. Y. P., "The revised two-factor study process questionnaire: R-SPQ-2F," British Journal of Educational Psychology, vol. 71, pp. 133-149, 2001.

[21] Levenson. H., "Multidimensional locus of control in psychiatric patients," Journal of Consulting and Clinical Psychology, vol. 41, pp. 397-404, 1973.

[22] Tabachnick. B. G., \& Fidell. L. S., "Using multivariate statistics (6. ed.)," Pearson, Upper Saddle River, 2013.

[23] Kline. R. B, "Principles and practice of structural equation modeling," The Guilford Press, New York, 2011.

[24] Kirby. J. R., Knapper. C., Lamon. P., \& Egnatoff. W. J., "Development of a scale to measure lifelong learning," International Journal of Lifelong Education, vol. 29(3), pp. 291-302, 2010.

[25] EC. European Commission, "European report on quality indicators of lifelong learning. Fifteen quality indicators," European Commission, Directorate-General for Education and Culture, Brussels, 2002. 
[26] Bryce. J., "Schools and lifelong learners," In J. Chapman, P. Cartwright \& E. J. McGilp (et al.), Lifelong learning, participation and equity (pp. 243-263), Springer, Dordrecht, 2006.

[27] Berberoğlu. G., \& Hei. L. M., "A comparison of university students' approaches to learning across Taiwan and Turkey," International Journal of Testing, vol. 3 (2), pp. 173-187, 2003.

[28] Trigwell. K., \& Prosser. M., "Improving the quality of student learning: the influence of learning context and student approaches to learning on learning outcomes," Higher education, vol. 22(3), pp. 251-266, 1991.

[29] Kennedy. P., "Learning cultures and learning styles: Myth-understandings about adult (Hong Kong) Chinese learners," International journal of lifelong education, vol. 21(5), pp. 430-445, 2002.

[30] Chang. M. M., \& Ho. C. M., "Effects of locus of control and learner-control on web-based language learning," Computer Assisted Language Learning, vol. 22(3), pp. 189-206, 2009.

[31] Severino. S., Aiello. F., Cascio. M., Ficarra. L., \& Messina. R., "Distance education: The role of self-efficacy and locus of control in lifelong learning," Procedia-Social and Behavioral Sciences, vol. 28, pp. 705-717, 2011.

[32] Joo. Y. J., Joung. S., \& Sim. W. J., "Structural relationships among internal locus of control, institutional support, flow, and learner persistence in cyber universities," Computers in Human Behavior, vol. 27(2), pp. 714-722, 2011.

[33] Parker. A., "A study of variables that predict dropout from distance education," International journal of educational technology, vol. 1(2), pp. 1-10, 1999.

[34] Garipağaoglu. B. C., "The effect of self-efficacy on the lifelong learning tendencies of Computer Education and Instructional Technologies students: A case study," Journal of Human Sciences, vol. 10(1), pp. 224-236, 2013.

[35] Leung. D. S., \& Liu. B. C., "Lifelong education, quality of life and self-efficacy of Chinese older adults," Educational Gerontology, vol. 37(11), pp. 967-981, 2011.

[36] Mlcek. S. H., "Competing knowledges in lifelong education," International journal of lifelong education, vol. 30(6), pp. 815-829, 2011.

\section{BIOGRAPHIES OF AUTHORS}

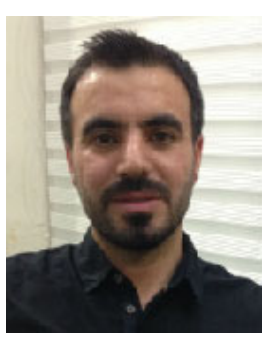

Dr. Karacabey is an assistant professor working at Harran University in Turkey. He completed a bachelor's degree in classroom teaching and worked as a classroom teacher. He got a master's degree in educational sciences from Harran University. He has got his Ph.D. degree in educational administration at Anadolu University in Turkey. His research interests are school dropouts, leadership, and organizational behavior.

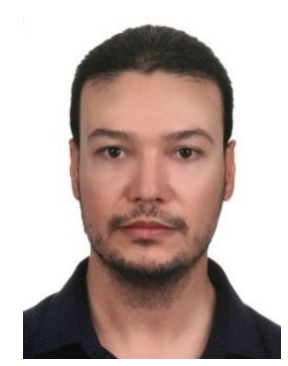

Dr. Bozkus is a researcher working at Artvin Coruh University in Turkey. He completed a bachelor's degree in science teaching and worked as a science teacher. By receiving a graduate education grant from the national ministry of education, he got a master's degree in educational leadership from the PennState University. He has got his Ph.D. degree in educational administration at Anadolu University in Turkey. His research interests are professional development of teachers, school development, leadership, and organizational behavior. 